\title{
BENCHMARKING: UMA FERRAMENTA IMPORTANTE PARA A COMPETITIVIDADE NO SETOR DE ARTESANATO
}

\section{BENCHMARKING: AN IMPORTANT TOOL FOR COMPETITIVENESS IN THE HANDICRAFT SECTOR}

\author{
Samanta Tatiane Nuciteli - samantanuciteli@gmail.com \\ Faculdade de Tecnologia (Fatec) - Taquaritinga - SP - Brasil \\ Guilherme Augusto Malagolli - guilherme.malagolli@fatectq.edu.br \\ Faculdade de Tecnologia (Fatec) - Taquaritinga - SP - Brasil
}

DOI: 10.31510/infa.v17i2.1064

Data de publicação: 18/12/2020

\section{RESUMO}

$\mathrm{O}$ artesanato é uma atividade economicamente relevante, que representa até 3\% do PIB de acordo com o IBGE (MDIC, 2020). Entretanto, o artesanato enfrenta uma concorrência cada vez mais intensa de produtos industrializados, que ganham em escala de produção e reduzem custos. Dados mostra que três em cada cinco artesões tem o artesanato como sua principal fonte de renda (Sebrae,2019)Em busca de inovação, os artesãos podem ter no Benchmarking uma estratégia importante para a competitividade. O objetivo desse artigo é apresentar um breve estudo sobre o Benchmarking como uma estratégia de competitividade para os produtos do artesanato. A metodologia de pesquisa contou com a revisão bibliográfica acerca do conceito e processo de Benchmarking, bem como uma pesquisa de campo com artesãos da cidade de Monte Alto-SP-Brasil e informações de instituições públicas oficiais, ligadas à promoção da atividade do artesanato no estado de São Paulo.

Palavras-chave: Benchmarking. Competitividade. Artesanato. Inovação.

\begin{abstract}
Handicrafts are an economically relevant activity, representing up to $3 \%$ of GDP according to the IBGE (MDIC, 2020). However, handicrafts face an increasingly intense competition from industrialized products, which gain in scale of production and reduce costs. Data shows that three out of five artisans have handicrafts as their main source of income (Sebrae, 2019). In search of innovation, artisans may have an important strategy for competitiveness in Benchmarking. The purpose of this article is to present a brief study on Benchmarking as a competitive strategy for handicraft products. The research methodology included a bibliographic review about the concept and process of Benchmarking, as well as a field research with artisans from the city of Monte Alto-SP-Brasil and information from official public institutions, linked to the promotion of the craft activity in the state of São Paulo.
\end{abstract}


Keywords: Benchmarking. Competitiveness. Handicrafts. Innovation.

\section{INTRODUÇÃO}

A sociedade atual tem assistido o surgimento de mercados cada vez mais competitivos, visando satisfazer as necessidades dos clientes e garantir a qualidade do fornecimento de seus produtos e serviços. Neste contexto, uma atividade antiga e altamente difundida, como o artesanato, passa por muitos desafios. Qual deve ser o apelo comercial do artesanato na medida em que os produtos industrializados inovam com frequência e, ainda, apresentam redução de preço na média em que se popularizam?

De acordo com dados do IBGE, o Brasil tem hoje 8 milhões de artesãos. O setor movimenta perto de R $\$ 50$ bilhões todos os anos, o que representa 3\% do PIB (MDIC, 2020). O setor, além de representativo do ponto de vista econômico, ainda é responsável pela renda de grande parte da população economicamente mais carente.

Entretanto, o setor de artesanato enfrenta uma concorrência cada vez maior de produtos industrializados. Costa (2010) afirma que o mercado atual vive uma nova realidade, a qual determina que as empresas busquem a todo momento vencer e se destacar frente a grande competitividade, senso assim é preciso inovar-se, buscar conhecimento e mudar aquilo que não está dando certo.

A necessidade de inovação atinge também o setor de artesanato, porém, sem que o artesão conte com a estrutura organizacional das grandes empresas. Neste sentido, a prática do Benchmarking pode representar uma alternativa para que os artesãos consigam inovar e adquirir novas habilidades na confecção de seus produtos.

Segundo Pinto (2007) o Benchmarking competitivo é um instrumento estratégico, em que as empresas buscam trocar informações com outras empresas para melhorar o processo produtivo e de bens de consumo e bens de serviço.

Neste contexto, o objetivo deste artigo é apresentar um breve estudo sobre o Benchmarking como uma estratégia de competitividade para os produtos do artesanato. A metodologia de pesquisa contou com a revisão bibliográfica acerca do conceito e processo de Benchmarking, bem como uma pesquisa de campo com artesãos da cidade de Monte Alto (SP) e será detalhada no item específico dedicado a ela. 


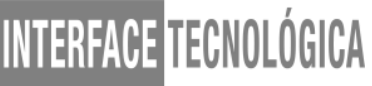

Como justificativa, compreender como artesãos podem permanecer em um mercado cada vez mais competitivo é de fundamental importância para a garantia de emprego e renda para uma parcela de trabalhadores manuais que dependem do artesanato para complementar a renda familiar ou, muitas vezes, como única fonte de renda.

\section{CONHECENDO O BENCHEMARKING}

Segundo Watson e Gregory (2010) os japoneses usam a palavra dantotsu "melhor do melhor" para definir benchmarking. Os autores definem o termo como um processo de alto aprimoramento cuja finalidade é procurar, encontrar e superar os pontos fortes dos concorrentes.

Segundo Veyrat (2018) o termo 'benchmarking' vem da palavra em inglês 'benchmark' que quer dizer 'referência'. De acordo com Araújo (2006) o benchmarking teve sua utilização como ferramenta organizacional no final da década de 70 iniciando a década de 1980. Entretanto, seu surgimento foi oriundo da Xerox Corporation, que definiu o termo e criou algumas ideias e objetivos relacionados, esse fator fez as empresas superasse suas constantes perdas no mercado. Sobre o benchmarking o autor afirma que essa ferramenta já existe desde os tempos de Frederik Taylor e seu uso foi extremamente importante para o Japão após a Segunda Guerra Mundial recuperasse a sua economia.

Por sua vez, Pinto (2007) define que o benchmarking é um instrumento de gestão, onde as empresas procuram desenvolver melhorias por meio da troca de experiência com empresas com atividades semelhantes e que apresentam desenvolvimento considerável.

Em outras palavras, Benchmarking é um processo em que se comparam os produtos, serviços e práticas empresariais entre os mais fortes concorrentes ou empresas reconhecidas como líderes (ZAIRI; LEONARD, 2005).

Lacomb e Heilborn (2003, p. 470) citam que segundo o chefe executivo da Xerox Corporation, David T. Kearns: "Benchmarking é um processo contínuo de medição de produtos, serviços e práticas em relação aos mais fortes concorrentes, ou às empresas reconhecidas como líderes em suas indústrias".

Sobre Benchmarking Araújo (2006, p. 235) define: 
É uma abordagem de gestão organizacional que conduz a tão desejada excelência, utilizando-se de procedimentos de investigação que pretendem reunir e adaptar as respostas encontradas por outras organizações. Longe de se igualar à mera cópia, revela alternativas valiosas de incrementos dos níveis de eficácia e eficiência.

Pinto (2007) explica que o benchmarking requer duas coisas: estabelecer metas e objetivos externos e aprender de outros, aprender quanto e aprender como.

Chiavenato (2003) afirma que o benchmarking tem como finalidade desenvolver a habilidade de gestores de visualizar no mercado as melhores práticas administrativas das empresas consideradas excelentes (benchmarks) em determinados aspectos, e assim comparar as mesmas práticas em evidências na empresa focalizada, avaliar a situação e identificar as oportunidades de mudança dentro da organização

Conforme Camp (1998) apud LIMA; OLIVEIRA (2018) assim como todo processo, é preciso que algumas etapas sejam seguidas para que o benchmarking seja aplicado, e explica que nesse método existem cinco fases genéricas que são planejamento, análise, integração, ação e maturidade.

A Figura 1 traz exemplo dos processos de benchmarking. 
Figura 1: Processos de Benchmarking

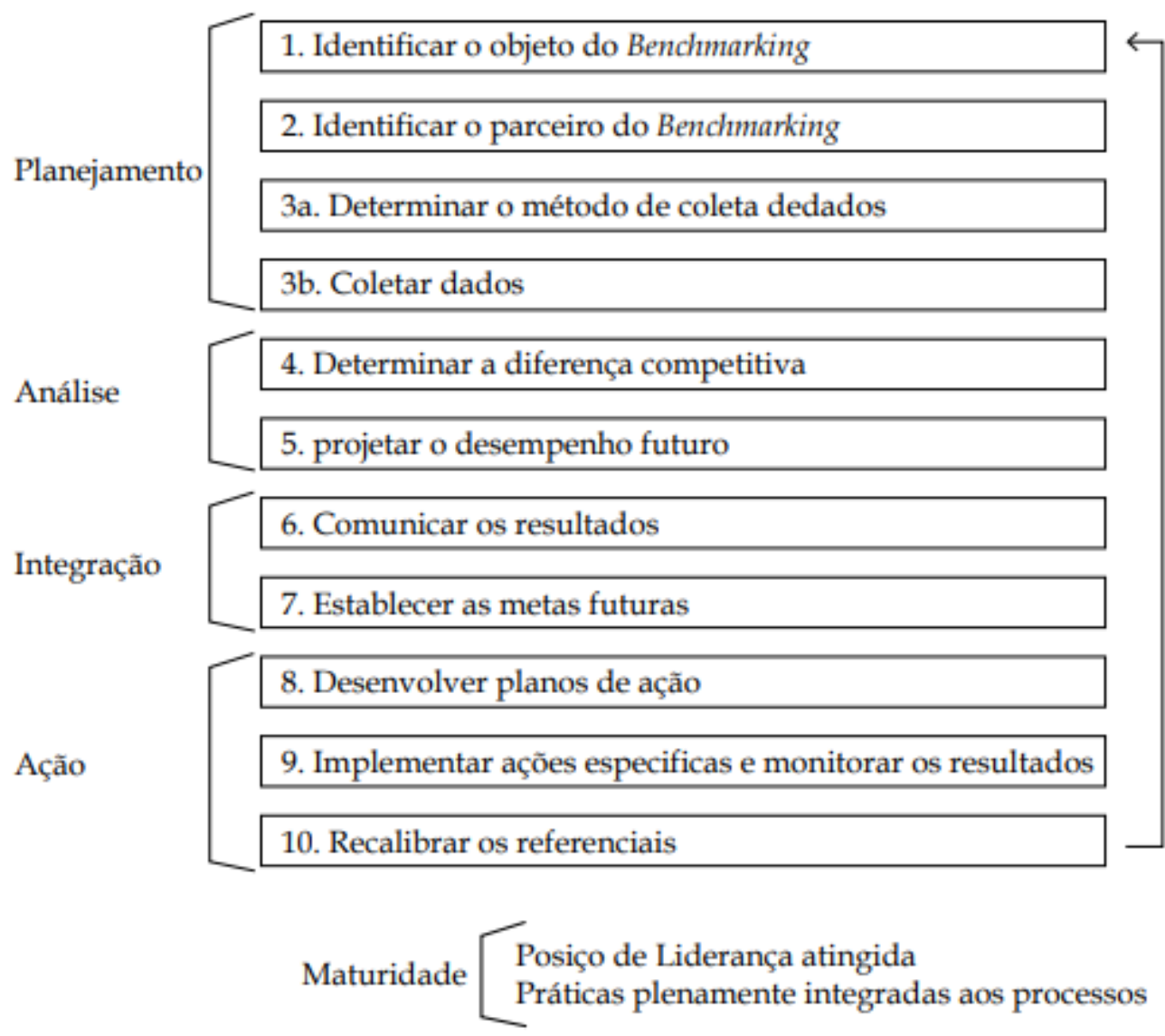

Fonte: Elaborado por Camp (1998, p.16) apud LIMA e OLIVEIRA, (2018; p.23)

Watson e Gregory (2010) ressaltam que existem 4 tipos de benchmarking que são: benchmarking interno; benchmarking competitivo; benchmarking funcional e benchmarking genérico.

\subsection{Benchmarking Interno}

De acordo com LIMA e OLIVEIRA (2018) o benchmarking interno configura as melhores práticas usadas dentro das organizações, em seus mais diversos departamentos, tendo como vantagem principal a obtenção de parcerias, com menores custos, bem como a valorização dos colaboradores internos.

Segundo Bardine (2017) esse modelo de benchmarking é usado pelas empresas que buscam evidenciar as melhores práticas usadas internamente na organização e estender para 
outros setores visando a melhoria. O autor ressalta que esse dentre os quatro tipos é o de mais fácil execução, uma vez que os dados que devem ser utilizados apresentam fácil disponibilidade e não há problemas de confiabilidade.

\subsection{Benchmarking competitivo}

De acordo com Araújo (2007) o benchmarking competitivo tem difícil prática, fator ocasionado porque as empresas visadas disputam o mesmo mercado, são concorrentes direta e muitas vezes não estão dispostas em ajudar a empresa concorrente. De acordo com o autor o foco principal do benchmarking competitivo está em medir métodos e características básicas de produção em relação aos seus concorrentes, e frente esta realidade, estabelecer melhorias para que possa se equiparar ou alcançar destaque em relação ao seu concorrente.

Bardine (2017) ressalta que no benchmarking competitivo as empresas e seus concorrentes buscam responder sobre o que estão fazendo, como estão fazendo e quão bem estão fazendo e sobre estas respostas buscar melhorias para o crescimento organizacional.

\subsection{Benchmarking Funcional}

O benchmarking funcional de acordo com Meneguelli et al., (2007) compara o setor com o melhor entre as empresas. Uma importante vantagem desse tipo de benchmarking é que as informações são obtidas com maior facilidade, já que as empresas são de ramos diferentes e não concorrem entre si. Segundo os autores as empresas envolvidas nesse processo compartilham informações de forma mais profissional.

Bardine (2017) ressalta que o benchmarking funcional é a forma mais usada, e que os ramos diferentes de atividades trazem novidades e técnicas interessantes que podem ser compartilhadas sem medo. Esse benchmarking segundo o autor é altamente produtivo.

\subsection{Benchmarking genérico}

Camp (1998) apud LIMA e OLIVEIRA (2018) explica que, nesse tipo de benchmarking, as empresas envolvidas desenvolvem atividades semelhantes. Esse processo pode ser por exemplo a análise desde a entrada de pedido na indústria até a entrega do 
produto. Esse tipo de processo requer uma conceituação mais ampla, pois busca o topo das melhorias.

Gomes (2004) esclarece que o benchmarking genérico apresenta similaridade ao benchmarking funcional em alguns aspectos, com exceção do fato de que focaliza processos de negócio multifuncionais.

\subsection{Vantagens do Benchmarking}

Araújo (2007) e Bardine (2017) afirmam que o uso do benchmarking como ferramenta para o encontro da melhoria contínua apresenta importante vantagem uma vez que pode ser utilizada em todos os setores da organização. Através de referências e experiências de outras empresas não há como perder tempo e ficar reinventando processos, basta entender o que a empresa concorrente tem de destaque e o que causa o seu crescimento de forma considerável e adequar a realidade organizacional a esse fator.

Bardine (2017) destaca que o benchmarking é uma renovação contínua muito favorável para o desenvolvimento da empresa. Os autores Bogan e English (1997), evidenciam as vantagens do benchmarking:

- Melhoria de qualidade organizacional

- $\quad$ Conduz operação de baixo custo

- $\quad$ Facilita o processo de mudanças

- $\quad$ Traz melhores ideias para os colaboradores

- $\quad$ Cria uma cultura aberta a novas ideias

- $\quad$ Serve como catalisador para o processo de aprendizagem

- $\quad$ Cria uma visão externa para a empresa

- Aumenta o nível organizacional de máximo

\subsection{Motivos que levam ao uso do benchmarking}

De acordo com Veyrat (2018) existem algumas importantes razões que fazem com que as empresas busquem o benchmarking. $\mathrm{O}$ autor explica que essa ferramenta geralmente é usada quando algum processo da empresa não está apresentando resultados satisfatórios e 
precisa ser aperfeiçoado. É preciso que antes de a empresa olhar as referências externas, tenha uma gestão eficiente para coletar os dados internos que está promovendo esta lacuna.

Outro motivo que leva a empresa a optar pelo benchmarking é quando há um forte concorrente e precisa-se entender os motivos que levaram ao fortalecimento da marca, dessa forma é necessário analisar seus processos, dados de desempenho e suas ações de comunicação e marketing. O benchmarking também pode ser usado para avaliar a posição de uma empresa em relação a outras, que muitas vezes tem um ramo além de sua área, mas que apresentam sucesso, por exemplo as de referências mundiais (VEYRAT, 2018).

\subsection{Exemplos do uso de benchmarking na prática}

Veyrat (2018) explica que o uso do benchmarking pode ser associado a diversas áreas da empresa e cita alguns exemplos. $\mathrm{Na}$ área de finanças por exemplo, que é uma área de extrema importância para a empresa, é possível usar o benchmarking para comparar os indicadores financeiros com o desempenho geral da indústria através de relatórios com pesquisas de mercado.

O marketing é outra área em que é usado o benchmarking, através de um consultor especializado nessa área é possível dar aos colaboradores orientações com base nas tendências usadas por outras organizações e que deram certo.

Bardine (2017) que as práticas governamentais também podem usar o benchmarking, uma vez que os estados ou países podem trocar experiências sobre boas práticas relacionadas as diversas áreas da gestão que podem assim contribuir para a melhoria de diversas áreas como: educação, saúde, transporte, agricultura, entre outras áreas.

\section{PROCEDIMENTOS METODOLÓGICOS}

De acordo com Gil (2010) e Vergara (2006) a pesquisa científica pode ter diversos aspectos. A pesquisa descritiva, por exemplo, procura observar, registrar, analisar, classificar e interpretar os fatos ou fenômenos (variáveis), sem que o pesquisador interfira neles ou os manipule. Este tipo de pesquisa tem como objetivo fundamental a descrição das características de determinada população ou fenômeno. Além disso, a pesquisa descritiva estabelece relações entre variáveis, visando analisar as características de um objeto de estudo. 
Uma das características de uma pesquisa descritiva é a utilização de técnicas padronizadas de coletas de dados, tais como o questionário e a observação sistemática, e instrumentos como a observação e o formulário.

Por outro lado, a pesquisa explicativa visa identificar os fatores que determinam ou contribuem para a ocorrência dos fenômenos. Segundo Gil (2006), este tipo de pesquisa é a que mais aprofunda o conhecimento da realidade, e, por isso mesmo, está fortemente calcada em métodos experimentais.

Este trabalho é caracterizado por uma pesquisa exploratório-descritiva, dadas as características do objeto de estudo, da utilização do estudo de caso e do levantamento de dados. A pesquisa é predominantemente descritiva em sua essência, porém, aborda um tema pouco explorado e utiliza-se de um estudo de caso, elementos típicos de uma pesquisa exploratória.

Para isso, foi realizada uma revisão bibliográfica acerca do conceito de Benchmarking, conforme visto no item 1. Além disso, foram realizadas entrevistas com artesãs de acessórios femininos e infantis residentes na cidade de Monte Alto (SP), bem como a coleta de dados de práticas artesanais de outros profissionais, com a consulta em sites de instituições ligadas ao tema, especialmente o da Subsecretaria do Trabalho Artesanal nas Comunidades - SUTACO, autarquia vinculada à Secretaria de Desenvolvimento Econômico, Ciência, Tecnologia e Inovação (SDECTI), do Estado de São Paulo.

\section{RESULTADOS E DISCUSSÃO}

Após a pesquisa de campo, notou-se que a concorrência do artesanato com os produtos industrializados tem se intensificado, especialmente no aspecto do preço. De acordo com as entrevistadas, é especialmente difícil reduzir o custo do trabalho artesanal, enquanto preço final dos produtos equivalentes da indústria está ganhando escala e se tornando mais acessíveis. Com isso, o artesanato fica dependente de um nicho de consumidores que compram por identificação com o trabalho artesanal.

Apesar da indústria não se caracterizar como uma parceira dos artesãos, os produtos industrializados, porém, passaram a ser uma fonte de inspiração para a inovação dentro do trabalho artesanal. Neste caso, o Benchmarking se caracteriza pelo desenvolvimento de novas 
habilidades e adaptações ao se inspirar em um produto e conseguir oferecer algo novo e diferente do que foi utilizado como inspiração. Esta prática, aproxima o conceito apresentado por autores como Chiavenato (2003), Pinto (2007) e Lima e Oliveira (2018) dentre outros apresentados na revisão teórica com o que se observa na estratégia das artesãs.

É de fundamental importância ressaltar que a prática da maioria dos profissionais do artesanato não é proveniente de um planejamento estruturado, baseado em autores selecionados e com métricas específicas. Dentro do pragmatismo, porém, observa-se que grande parte do processo de Benchmarking apresentado por Camp (1998) apud LIMA e OLIVEIRA (2018) é contemplada neste caso conforme exposto anteriormente no artigo (Figura 1, pág. 4). Embora não haja um parceiro formal, as etapas do planejamento são atendidas e não constituem um empecilho para a sequência do processo.

$\mathrm{Na}$ etapa da integração, vale ressaltar que a difusão da inovação é rápida e, assim, em pouco tempo outros artesãos incorporam as habilidades e passam a oferecer produtos diferentes. Esta disseminação rápida das novas práticas e habilidades estimula que os artesãos, especialmente do segmento de acessórios femininos e infantis, busquem sempre por novidades e tendências de moda vindas da indústria. Assim, o benchmarking acaba se tornando uma prática natural e buscada por estes profissionais como forma de se manter no mercado e aumentar a sua competitividade frente aos produtos industrializados.

\section{CONSIDERAÇÕES FINAIS}

O artesanato é uma atividade que enfrenta forte concorrência de produtos industrializados. Em alguns segmentos, os ganhos de escala na indústria e a popularização de produtos permitiram a queda dos preços, dificultando ainda mais a concorrência para os artesãos. A alguns segmentos do artesanato, restou um mercado consumidor restrito, que compra por identificação com a prática do artesão.

Neste contexto a inovação passou a ser imprescindível para que os artesãos permaneçam no mercado e consigam concorrer com os outros produtos industrializados. Nesta busca pela inovação, muitos artesãos utilizam o Benchmarking, ainda que de forma pragmática. De acordo com as informações pesquisadas, os produtos industrializados passaram a ser um modelo para a inovação dentro do trabalho artesanal. Neste caso, o Benchmarking se caracteriza pelo desenvolvimento de novas habilidades e adaptações ao se 
inspirar em um produto e conseguir oferecer algo novo e diferente do que foi utilizado como inspiração. Assim, observou-se que o comportamento destes artesãos tem uma proximidade com o conceito de Benchmarking apresentado por autores como Chiavenato (2003), Pinto (2007) e Lima e Oliveira (2018) dentre outros.

Utilizar as referências de empresas de sucesso no mercado tem sido uma importante estratégia para crescimento. As experiências das outras organizações e os planos usados para a promoção de crescimento podem servir como base para empresas que buscam acertar e assim manter-se no mercado.

Vale ressaltar que, com o uso do benchmarking, nem sempre é preciso analisar somente o concorrente de sucesso, mas é possível olhar internamente para dentro do próprio mercado de artesanato e buscar referências em setores que estão apresentando resultados positivos. Desta forma a disseminação da inovação é rápida e traz um ganho de habilidades e novas práticas para todo o setor.

Entender as estratégias dos concorrentes e buscar através desse conhecimento, estímulos para as mudanças é um importante fator para um mercado onde a competitividade tem ganhado um espaço considerável.

\section{REFERÊNCIAS}

ARAÚJO, 1. C. G. Organização, Sistemas e Métodos e as Tecnologias de Gestão Organizacional. 2ed. São Paulo: Atlas, 2006.

BARDINE, R. Benchmarking. 2017. Disponível em: $<$ https://www.coladaweb.com/administracao/benchmarking $>$. Acesso em: 10 fev. 2020.

BOGAN, C. E.; ENGLISH, M. J. Benchmarking: aplicações prática e melhoria contínua. São Paulo: Makron Books, 1997.

CAMP. Robert C. Benchmarking - O Caminho da Qualidade Total. 3.ed. São Paulo: Pioneira, 1998.

CHIAVENATO, I. Introdução à Teoria Geral da Administração. 7 ed. Rio de Janeiro: Elsevier, 2003.

COSTA, Fernando Nogueira da. Finanças dos Trabalhadores. Campinas: Unicamp. IE, jul. 2010. (Texto para Discussão, n. 182).

GIL, A. C. Como elaborar projetos de pesquisa. 5. ed. São Paulo: Atlas, 2010 
GOMES, P. A evolução do conceito de qualidade: dos bens manufaturados aos serviços de informação, Cadernos BAD, v. 2, p. 6-18, 2004.

LACOMBE, F.; HEILBORN, G. Administração: Princípios e Tendências. São Paulo: Saraiva, 2003.

LIMA, A. R.; OLIVEIRA, R. S. O processo de benchmarking: um estudo em empresas de construção civil no município de João Pessoa. Escr. Contab. Adm., Bahia Blanca , v. 9, n. 2, 2018 . Disponível em:

$<$ http://bibliotecadigital.uns.edu.ar/scielo.php?script=sci_arttext\&pid=S1853-

$20552018002200002 \& \operatorname{lng}=$ es\&nrm=iso $>$. Acesso em 30 out. 2020.

MDIC. Ministério da Indústria e Comércio. (2020). Disponível em $<$ http://www.mdic.gov.br/index.php/component/content/article?id=3201 $>$. Acesso em 16 out. 2020 .

MENEGUELLI, Marcelle Fernandes et al. Benchmarking: Ferramenta a Serviço da inovação. Revista eletrônica da Faculdade Metodista Granbery, n. 3, 2007.

PINTO, L. F. da S. O homem, o arco e a flecha: em direção à teoria geral da estratégia. Brasília: Edictora Senac - DF, 2007.

SEBRAE. Serviço Brasileiro de Apoio às Micro e Pequenas Empresas. (2019) Disponível em $\quad<$ http://www.agenciasebrae.com.br/sites/asn/uf/NA/artesanato-sera-motor-dedesenvolvimento- do-turismo $>$. Acesso em 13 fev. 2021.

SUTACO. Subsecretaria do Trabalho Artesanal nas Comunidades. Disponível em $<$ https://www.saopaulo.sp.gov.br/orgaos-e-entidades/autarquias/sutaco $>$. Acesso em 16 out. 2020.

VERGARA, S. C. Projetos e relatórios de pesquisa em administração. São Paulo: Atlas, 2006.

VEYRAT, P. Exemplos de benchmarking: 7 maneiras de trocar informações para crescer. 2018. Disponível em: <https://blog.lahar.com.br/marketing-digital/exemplos-debenchmarking >. Acesso em 20 jan. 2020.

WATSON, H. GREGORY, P.A. Benchmarking Estratégico.Editora Makron Books. 2010 ZAIRI, M.; LEONARD, P. Benchmarking Prático - O Guia Completo. São Paulo: Atlas, 2005. 